\title{
PENGEMBANGAN MODEL LITERASI DIGITAL DALAM PEMBELAJARAN KITAB KUNING DI MA'HAD AL-JAMIAH UIN MAULANA MALIK IBRAHIM MALANG
}

\author{
Muhammad Yasin Fatchul Barry* \\ *UIN Maulana Malik Ibrahim Malang \\ myasinfb@uin-malang.ac.id
}

\begin{abstract}
Development of digital literacy is needed not only in formal education, but also for nonformal education such as pesantren. Therefore this study aims to describe the pattern of digital literacy development among ma'had al-jamiah students of Maulana Malik Ibrahim State Islamic University of Malang, as well as to explain the effectiveness of the use of the yellow book digital literacy model. This study uses the modified Borg and Gall R\&D method, and the type of experimental research carried out to determine the effectiveness of product use. This research results in exposure to digital literacy in the ma'had that has been developed and the use of digital literacy of the yellow book through an android application that has a significant effect in increasing the ability of students to study the yellow book.
\end{abstract}

Keywords: Digital Literacy, Yellow Book, Ma'had Al-Jamiah

\section{A. PENDAHULUAN}

Literasi di era revolusi industri 4.0 ditandai dengan penggunaan teknologi dan bertransformasi menjadi literasi digital. Sabatino (2014) dalam (Blevins, 2018) menekankan bahwa penggunaan teknologi digital membeerikan kesempatan baru dan tantangan untuk menyusun dan menyebarkan teks dalam bentuk literasi digital. Peran pendidik sekarang adalah bagaimana cara untuk memudahkan pembelajar dalam mengembangkan diri dalam bidang literasi dengan menyediakan berbagai media pembelajaran salah satunya yang dekat dengan generasi milenial sekarang yaitu aplikasi android. 


\section{Muhammad Yasin Fatchul Barry}

Paul Gilster, penulis buku Digital Literacy (1997) mengartikan literasi digital sebagai kemampuan seseorang tidak hanya memahami informasi, tetapi juga megkritisi dan mengintegrasikan informasi kedalam berbagai format yang dapat diakses melalui jaringan internet (Pool, t.t.). Dengan kata lain kemampuan seseorang berpikir kritis terhadap sebuah informasi yang ia temukan di internet. Informasi yang dimaksud tidak hanya berupa teks, akan tetapi dapat berupa video, audio, foto dan lain sebagainya. Wilhelm (2004) dalam (Techataweewan \& Prasertsin, 2018) lebih memperinci bahwa seseorang yang literat berarti mampu mengakses, mengatur, mengintegrasikan, mengevaluasi dan bahkan menciptakan informasi.

Literasi digital dalam dunia pendidikan sudah banyak dikembangkan oleh peneliti-peneliti sebelumnya. Diantaranya adalah penelitian tentang pandangan guru maupun siswa terhadap perkembangan literasi menjadi literasi digital (Porat, Blau, \& Barak, 2018),(List, 2019), (Antonelli dkk., 2019)dan (López, 2020). Sedangkan beberapa peneliti lainnya mengembangkan literasi digital dalam ranah sekolah (Ting, 2015), (Kaeophanuek, Jaitip, \& Nilsook, 2018), (Techataweewan \& Prasertsin, 2018) dan (Lazonder, Walraven, Gijlers, \& Janssen, 2020). Diantara penelitian liteasi digital diatas yang menarik perhatian adalah penelitian tentang pengembangan literasi digital santri (Putra, Muchtarom, \& Rejekiningsih, 2019).

Penelitian terakhir bertujuan mendeskripsikan perkembangan keterampilan literasi digital santri di ma'had (pondok pesantren) bahwa pembelajaran 


\section{PENGEMBANGAN MODEL LITERASI DIGITAL DALAM PEMBELAJARAN KITAB KUNING DI MA'HAD AL-JAMIAH UIN MAULANA MALIK IBRAHIM MALANG}

menggunakan literasi digital secara efektif membantu santri dalam mengembangkan keterampilan mereka menggunakan teknologi, selain itu dapat membantu santri dalam memproses informasi melalui media digital. Mengacu pada kesuksesan penelitian tersebut diatas, maka peneliti mengarahkan tujuan penelitian ini kepada pendeskripsian perkembangan literasi digital serta pengembangan liteasi digital kitab kuning dengan aplikasi android bagi santri Ma'had Al Jamiah UIN Maulana Malik Ibrahim Malang.

Sama halnya dengan pembelajaran di pesantren, pembelajaran di Ma'had Al Jamiah juga menerapkan kegiatan pengajian kitab kuning atau kitab turats, semua mahasiswa yang menetap di Ma'had diwajibkan untuk mengikuti kegiatan tersebut dan ditargetkan untuk menguasai kitab kuning dengan baik sesuai dengan pembahasannya. Akan tetapi timbul beberapa masalah diantaranya adalah banyaknya mahasiswa yang belum bisa membaca kitab kuning dan menguasai pembahasannya setelah mengikuti kegiatan. Hal itu banyak disebabkan karena background studi mereka yang tidak pernah menempuh pendidikan di pesantren, singkatnya waktu menetap di Ma'had.

Solusi dari masalah tersebut adalah mengembangkan model literasi digital pada kitab kuning yang digunakan mahasantri tersebut. Pengembangan berupa aplikasi berbasis android dipilih karena kedekatannya dengan kehidupan santri sekarang yang merupakan digital native. Selain alasan diatas, kurangnya program yang menunjang kegiatan pengajian kitab kuning serta kurangnya motivasi 


\section{Muhammad Yasin Fatchul Barry}

mereka dalam mengikuti pengajian kitab kuning mendorong peneliti untuk mengembangkan kitab kuning berbasis aplikasi android agar pembelajaran kitab kuning menjadi lebih menyenangkan dan lebih fleksibel untuk santri Ma'had Al Jamiah UIN Maulana Malik Ibrahim Malang.

\section{B. METODE PENELITIAN}

Pendekatan campuran antara kualitatif dan kuantitatif digunakan sebagai rancangan penelitian ini. Model penelitian pengembangan Borg and Gall digunakan dengan beberapa modifikasi. untuk mendeskripsikan pengembangan Literasi Digital dalam pembelajaran kitab kuning di Ma'had Al Jamiah UIN Maulana Malik Ibrahim Malang digunakan pendekatan kualtitatif sedangkan untuk menguji keefektifitasan penerapan pola pengembangan Literasi Digital dalam pembelajaran Kitab kuning di Ma'had Al Jamiah UIN Maulana Malik Ibrahim Malang digunakan pendekatan kuantitatif.

Secara lebih terperinci, tahapan model penelitian R\&D Borg and Gall yang telah dimodifikasi akan ditampilkan dalam tabel, sebagai berikut :

\begin{tabular}{|c|c|c|}
\hline No & Tahapan & Kegiatan \\
\hline 1 & $\begin{array}{l}\text { Penelitian dan } \\
\text { pengumpulan } \\
\text { informasi awal }\end{array}$ & $\begin{array}{l}\text { Penulis melakukan penelaahan buku dan } \\
\text { jurnal yang berkaitan dengan literasi digital } \\
\text { kemudia melakukan pengamatan di tempat } \\
\text { penelitian dan mempersiapkan laporan awal. }\end{array}$ \\
\hline 2 & Planning & $\begin{array}{l}\text { menyusun tujuan khusus untuk menetapkan } \\
\text { langkah langkah yang akan ditempuh, }\end{array}$ \\
\hline
\end{tabular}




\begin{tabular}{|c|c|c|}
\hline & & $\begin{array}{l}\text { kemudian menentukan desain dan uji coba } \\
\text { skala kecil. Di langkah ini, peneliti meneliti } \\
\text { mahasantri. }\end{array}$ \\
\hline 3 & $\begin{array}{l}\text { Pengembangan } \\
\text { format produk awal }\end{array}$ & $\begin{array}{l}\text { Mengembangkan bentuk awal dari bahan } \\
\text { ajar qawaid yang akan didesain dalam } \\
\text { bentuk peta konsep. Pada langkah ini, } \\
\text { peneliti akan mendesain produk dengan } \\
\text { berdasarkan materi materi yang } \\
\text { berhubungan Literasi Digital }\end{array}$ \\
\hline 4 & Validasi data & $\begin{array}{l}\text { Penulis melakukan validasi kepada ahli } \\
\text { materi dan ahli desain produk. }\end{array}$ \\
\hline 5 & Uji coba awal & $\begin{array}{l}\text { Melakukan uji coba awal dengan melibatkan } \\
\text { 3-5 mahasantri. Kemudian mengumpulkan } \\
\text { dan menganalisis hasil wawancara, observasi } \\
\text { dan angket. }\end{array}$ \\
\hline 6 & Revisi produk & $\begin{array}{l}\text { melakukan revisi produk berlandas pada } \\
\text { hasil uji coba awal tersebut, dan atas dasar } \\
\text { masukan dari para validator yaitu para pakar } \\
\text { yang kompeten di bidang pengembangan. }\end{array}$ \\
\hline 7 & Uji coba lapangan & $\begin{array}{l}\text { Uji lapangan ini melibatkan mahasantri } \\
\text { dalam pembelajaran kitab kuning di Ma'had } \\
\text { Al-Jamiah. }\end{array}$ \\
\hline 8 & Revisi produk & $\begin{array}{l}\text { Melakukan revisi produk berdasarkan hasil } \\
\text { uji coba lapangan. }\end{array}$ \\
\hline
\end{tabular}

Teknik pengumpulan data melalui wawancara dengan pimpinan ma'had Al Jamiah serta tim pengajar dengan wawancara terstruktur, observasi denganmenggunakan 2 jenis observasi yaitu observasi partisipan dan non partisipan, 


\section{Muhammad Yasin Fatchul Barry}

angket diukur dengan menggunakan analisis statistik. Untuk mengukur tingkat keefektifitasan produk terhadap peningkatan kemampuan mahasantri dilakukan eksperiment one group pretest-posttest, serta tes yang diukur menggunakan rumus t-test (Arikunto, 2010 ).

\section{PEMBAHASAN}

1. Mutu Pola Perkembangan Literasi Digital dalam Pembelajaran Kitab Kuning di Ma'had Al-Jamiah UIN Maulana Malik Ibrahim Malang

Peneliti melakukan pengamatan terhadap proses belajar dan hasil belajar para mahasantri di ma'had. Dari observasi tersebut, peneliti menemukan beberapa hasil sebagai berikut :

a. Pengajar (mu'allim) masih mempraktekkan cara lama dalam proses pembelajarannya, membacakan teks kitab kuning, mengartikan dan kemudian menjelaskan pemahamannya.

b. Pengajar (mu'allim) tidak memanfaatkan papan tulis sebagai media untuk mempermudah menjelaskan materi yang disampaikannya.

c. Pengajar masih jarang melakukan feedback atau memberikan pertanyaan kepada mahasantri setelah menjelaskan materi nya.

d. Dikarenakan jumlah peserta ta'lim per kelas sampai 30 mahasantri, seringkali beberapa dari mereka kurang bisa atau bahkan tidak bisa memahami penjelasan mu'allim dengan baik. 
e. Sebagian besar mahasantri masih belum mengetahui arti teks materi kitab yang dikaji di ta'lim afkar, dan mereka hanya mengandalkan penjelasan dari muallim.

f. Belum ada program pengayaan tambahan atau semacam diskusi bersama untuk para mahasantri yang membahas materi setelah selesai mengikuti ta'lim afkar.

g. Waktu pelaksanaan ta'lim di malam hari setelah shalat isya membuat beberapa mahasantri kurang bersemangat dikarenakan capek setelah beraktifitas sejak pagi mengikuti perkuliahan reguler dan perkuliahan bahasa arab (PKPBA).

h. Banyak dari mahasantri tidak bisa membaca dan memahami materi kitab dikarenakan background mereka yang tidak pernah di pondok pesantren, melainkan hanya lulusan SMA dan SMK.

Peneliti juga melakukan wawancara kepada pengajar (muallim) ta'lim afkar di ma'had al-jamiah uin maulana malik Ibrahim malang. Wawancara dilakukan dengan mengajukan beberapa pertanyaan yang berhubungan dengan pembelajaran ta'lim afkar (kitab kuning) dan terkait cara pengajar dalam proses pembelajaran. Hasil wawancara tersebut menyatakan bahwa banyak dari pengajar masih menggunakan cara lama atau metode klasik dalam mengajarkan materi kitab kuning di ma'had, sedikit dari mereka yang menggunakan metode langsung. 


\section{Muhammad Yasin Fatchul Barry}

Banyak dari pengajar tidak menggunakan media pembelajaran dalam mengajar kitab di ma'had, dan sedikit dari mereka yang menggunakan media yang sederhana. Mayoritas para pengajar melakukan evaluasi setelah menyampaikan materi kitab, dengan cara bertanya langsung tentang ringkasan materi yang sudah dijelaskan oleh pengajar, sedangkan sedikit dari mereka menyiapkan pertanyaan tertulis di kertas untuk diberikan ke mahasantri.

Semua pengajar berpendapat bahwa kitab yang dikaji di ma'had sudah sesuai dan layak untuk dipelajari. Banyak dari pengajar (muallim) tidak menemukan kesulitan dalam memahami materi, mereka kesulitan dalam mencari model yang lebih baik untuk lebih memudahkan pemahaman mahasantri. Sedikit dari muallim merasa kesulitan karena perlu mengartikan setiap kata kepada mahasantri dikarenakan level kelas bawah.

Semua pengajar menganggap dan menyakini bahwa materi-materi tersebut sangat penting untuk pengetahuan dasar mahasantri dan menyangkut aktifitas sehari-hari.Beberapa muallim menyarankan diadakannya pengayaan materi setelah ta'lim berlangsung, dan beberapa dari mereka juga menyarankan membuat program khusus untuk mengatasi masalah tersebut. Beberapa muallim berpendapat bahwa proses pembelajaran masih bisa berjalan dengan baik, tetapi beberapa dari mereka mengeluhkan jadwal malam hari, dikarenakan beberapa mahasiswa merasa capek setelah mengikuti kegiatan sejak pagi sampai sore. 


\section{PENGEMBANGAN MODEL LITERASI DIGITAL DALAM PEMBELAJARAN KITAB KUNING DI MA'HAD AL-JAMIAH UIN MAULANA MALIK IBRAHIM MALANG}

Beberapa muallim melakukan komunikasi secara personal kepada mahasantri, dan memberikan latihan khusus, selain itu perlu menjelaskan materi dengan pelan dan komprehensif. Beberapa yang lain menawarkan kepada mahasantri untuk mengeksplorasi penjelasan/mengulang penjelasan dari muallim. perlu forum diskusi antar muallim lebih intens.

Para pengajar juga mengungkapkan saran-saran yang sekiranya dapat mendorong kemajuan kegiatan literasi di ma'had al-jamiah seperti perlu adanya program pengayaan untuk muallim untuk menyatukan pemahaman materi sesuai tujuan pembelajaran, perlu disiapkan media pembelajaran untuk menunjang kegiatan ta'lim, perlu diagendakan secara inten kegiatan untuk mempraktekkan materi yang sudah dipelajari oleh mahasantri serta perlu dibuat program pengayaan/forum untuk mahasiswa bisa lebih baik memahami materi, tes klasifikasi agar lebih teliti lagi karena beberapa mahasiswa yang kompetensi nya tidak sesuai dengan kelasnya dan perrlu disiapkan perpustakaan di ma'had agar bias diakses oleh mahasantri terkait materi kitab.

Dari hasil observasi dan wawancara diatas dapat disimpulkan bahwa kegiatan literasi telah berjalan dilingkungan ma'had al-jamiah, akan tetapi perkembangan dari literasi ke literasi digital kurang muncul. Padahal hasil angket yang disebar ke mahasantri meyatakan bahwa mereka memerlukan sebuah cara agar dapat mempelajari kitab kuning secara menarik dan mudah dipahami. Maka dari itu 


\section{Muhammad Yasin Fatchul Barry}

pengembangan pembelajaran kitab kuning dengan model digital literasi perlu dilakukan.

\section{Efektifitas pengembangan Literasi Digital dalam Meningkatkan Kompetensi Mahasantri dalam Pembelajaran Kitab Kuning di Ma'had Al-Jamiah.}

Setelah diadakan studi pendahuluan tentang urgensi pembuatan produk dalam rangka mengembangkan digitalliterasi dalam pembelajaran kitab kuning di ma'had al-jamiah, maka peneliti telah mengembangkan produk aplikasi berbasis android untuk pelajaran kitab kuning. Setelah uji coba awal dan revisi produk, maka uji coba lapangan juga telah dilakukan peneliti untuk mengetahui keefektifan produk aplikasi berbasis android dalam meningkatkan kemampuan mahasantri dalam mempelajari kitab kuning. Eksperimen one group pretest-posttest dilakukan terhadap 50 mahasantri ma'had al-jamiah UIN Maulana Malik Ibrahim Malang dengan hasil bahwa model literasi digital dengan aplikasi berbasis android pada pembelajaran kitab kuning menunjukkan peningkatan yang signifikan terhadap hasil belajar mahasantri.

Pemaparan hasil diatas menekankan bahwa literasi digital di kalangan mahasantri ma'had al-jamiah UIN Maulana Malik Ibrahim Malang sudah berkembang walaupun masih sebatas literasi saja. Hal ini sejalan dengan penelitian (Anwar, Komariah, \& Rahman, 2017) yang menyatakan bahwa santri sudah didorong untuk menggunakan internet sebagai salah satu sumber informasi, mereka mendapatkan informasi yang dibutuhkan melalui internet, buku, koran, majalah dan 


\section{PENGEMBANGAN MODEL LITERASI DIGITAL DALAM PEMBELAJARAN KITAB KUNING DI MA'HAD AL-JAMIAH UIN MAULANA MALIK IBRAHIM MALANG}

bahkan dari lingkungan kultur sosial tempat mereka tinggal, yang kemudia informasi tersebut diolah dan disampaikan kepada masyarakat dengan harapan para santri dapat menjadi agen perubahan bangsa.

Selain itu, penelitian (Setyaningsih, Abdullah, Prihantoro, \& Hustinawaty, 2019) juga memaparkan penguatan-penguatan literasi digital dalam lingkup pesantrean, yaitu berupa pemanfaatan media e-learning dalam proses pembelajaran karena dengan adanya penggunaan media dalam e-learning mereka dituntut untuk mengembangkan keterampilan individu dalam berliterasi. Literasi digital melalui elearning ini dapat menguatkan kemampuan literasi karena mengandung tiga hal yaitu kemampuan penggunaan alat, kemampuan berpikir kritis dan kemampuan berkomuniksi.

Pengembangan literasi digital kitab kuning di ma'had al-jamiah memberikan kontribusi yang positif terhadap peningkatan kemampuan mahasantri dalam mempelajari kitab kuning. Literasi digital memberikan dampak positif bagi pemuda Indonesia dalam mengetahui, memahami dan mengevaluasi informasi karena melalui media, sehingga menumbuhkan sikap peduli terhadap bangsa (Silvana \& Darmawan, 2018). Maka dari itu pelatihan dan pengembangan terhadap literasi digital yang dapat berkontribusi pada pengembangan pemuda Indonesia harus terus dilakukan, dengan tujuan melatih dan mebiasakan pemuda Indonesia menghadapi perkembangan zaman.

\section{KESIMPULAN}




\section{Muhammad Yasin Fatchul Barry}

Penelitian ini menghasilkan produk aplikasi berbasis android untuk pembelajaran kitab kuning di ma'had al-jamiah UIN Maulana Malik Ibrahim Malang. Pengembangan ini dilakukan sebagai upaya penanaman sikap literat melalui literasi digital pada mahasantri UIN Malang. Penelitian lanjutan diperlukan untuk pengembangan-pengembangan produk literasi digital diberbagai buku lainnya di ma'had al-Jamiah.

\section{E. DAFTAR PUSTAKA}

Arikunto.Suharsimi. 2010. Prosedur Penelitian Suatu Pendekatan Praktek (Edisi Revisi).Jakarta : PT. Rineka Cipta.

Antonelli, D., D'Addona, D. M., Maffei, A., Modrak, V., Putnik, G., Stadnicka, D., \& Stylios, C. (2019). Tiphys: An Open Networked Platform for Higher Education on Industry 4.0. Procedia CIRP, 79, 706-711. https://doi.org/10.1016/j.procir.2019.02.128

Anwar, R. K., Komariah, N., \& Rahman, M. T. (2017). Pengembangan Konsep Literasi Informasi Santri: Kajian di Pesantren Arafah Cililin Bandung Barat. Wawasan: Jurnal Ilmiah Agama dan Sosial Budaya, 2(1), 131-142. https://doi.org/10.15575/jw.v2i1.964

Blevins, B. (2018). Teaching Digital Literacy Composing Concepts: Focusing on the Layers of Augmented Reality in an Era of Changing Technology. Computers and Composition, 50, 21-38. https:// doi.org/10.1016/j.compcom.2018.07.003

Lazonder, A. W., Walraven, A., Gijlers, H., \& Janssen, N. (2020). Longitudinal assessment of digital literacy in children: Findings from a large Dutch singleschool study. Computers \& Education, 143, 103681. https://doi.org/10.1016/j.compedu.2019.103681

List, A. (2019). Defining digital literacy development: An examination of pre-service teachers' beliefs. Computers \& Education, 138, 146-158. https://doi.org/10.1016/j.compedu.2019.03.009

López, M. M. (2020). Linking Community Literacies to critical literacies through community language and literacy mapping. Teaching and Teacher Education, 87, 102932. https://doi.org/10.1016/j.tate.2019.102932

Pool, C. R. (t.t.). A New Digital Literacy: A Conversation with Paul Gilster. 7.

Porat, E., Blau, I., \& Barak, A. (2018). Measuring digital literacies: Junior high-school students' perceived competencies versus actual performance. Computers $\mathcal{E}$ Education, 126, 23-36. https://doi.org/10.1016/j.compedu.2018.06.030 


\section{PENGEMBANGAN MODEL LITERASI DIGITAL DALAM PEMBELAJARAN KITAB KUNING DI MA'HAD AL-JAMIAH UIN MAULANA MALIK IBRAHIM MALANG}

Putra, A. L., Muchtarom, M., \& Rejekiningsih, M. T. (2019). Using Digital Media in Civics Education Learning Subject to Develop Santri's Digital Literacy at the Age of Technology Disruption. International Journal of Engineering and Advanced Technology, $8(5 \mathrm{C})$,

818-823. https://doi.org/10.35940/ijeat.E1115.0585C19

Setyaningsih, R., Abdullah, A., Prihantoro, E., \& Hustinawaty, H. (2019). MODEL PENGUATAN LITERASI DIGITAL MELALUI PEMANFAATAN ELEARNING. Jurnal ASPIKOM, 3(6), 1200. https://doi.org/10.24329/aspikom.v3i6.333

Silvana, H., \& Darmawan, C. (2018). PENDIDIKAN LITERASI DIGITAL DI KALANGAN USIA MUDA DI KOTA BANDUNG. PEDAGOGIA, 16(2), 146. https://doi.org/10.17509/pdgia.v16i2.11327

Techataweewan, W., \& Prasertsin, U. (2018). Development of digital literacy indicators for Thai undergraduate students using mixed method research. Kasetsart Journal of Social Sciences, 39(2), 215-221. https://doi.org/10.1016/j.kjss.2017.07.001

the Faculty of Education, Chulalongkorn University, Bangkok, Thailand, Kaeophanuek, S., Jaitip, N.-S., \& Nilsook, P. (2018). How to Enhance Digital Literacy Skills among Information Sciences Students. International Journal of Information and Education Technology, 8(4), 292-297. https://doi.org/10.18178/ijiet.2018.8.4.1050

Ting, Y.-L. (2015). Tapping into students' digital literacy and designing negotiated learning to promote learner autonomy. The Internet and Higher Education, 26, 25-32. https:// doi.org/10.1016/j.iheduc.2015.04.004 


\section{Muhammad Yasin Fatchul Barry}

